\title{
The use of EEG parameters as predictors of drug effects on cognition
}

Citation for published version (APA):

Blokland, A., Prickaerts, J., van Duinen, M., \& Sambeth, A. (2015). The use of EEG parameters as predictors of drug effects on cognition. European Journal of Pharmacology, 759, 163-168. https://doi.org/10.1016/j.ejphar.2015.03.031

Document status and date:

Published: 15/07/2015

DOI:

10.1016/j.ejphar.2015.03.031

Document Version:

Publisher's PDF, also known as Version of record

Document license:

Taverne

Please check the document version of this publication:

- A submitted manuscript is the version of the article upon submission and before peer-review. There can be important differences between the submitted version and the official published version of record.

People interested in the research are advised to contact the author for the final version of the publication, or visit the DOI to the publisher's website.

- The final author version and the galley proof are versions of the publication after peer review.

- The final published version features the final layout of the paper including the volume, issue and page numbers.

Link to publication

\footnotetext{
General rights rights.

- You may freely distribute the URL identifying the publication in the public portal. please follow below link for the End User Agreement:

www.umlib.nl/taverne-license

Take down policy

If you believe that this document breaches copyright please contact us at:

repository@maastrichtuniversity.nl

providing details and we will investigate your claim.
}

Copyright and moral rights for the publications made accessible in the public portal are retained by the authors and/or other copyright owners and it is a condition of accessing publications that users recognise and abide by the legal requirements associated with these

- Users may download and print one copy of any publication from the public portal for the purpose of private study or research.

- You may not further distribute the material or use it for any profit-making activity or commercial gain

If the publication is distributed under the terms of Article $25 \mathrm{fa}$ of the Dutch Copyright Act, indicated by the "Taverne" license above, 
Review

\title{
The use of EEG parameters as predictors of drug effects on cognition
}

\author{
Arjan Blokland ${ }^{\mathrm{a}, *}$, Jos Prickaerts ${ }^{\mathrm{b}}$, Marlies van Duinen ${ }^{\mathrm{b}}$, Anke Sambeth ${ }^{\mathrm{a}}$ \\ a Department of Neuropsychology and Psychopharmacology, Faculty of Psychology and Neuroscience, European School of Neuroscience (EURON), Maastricht \\ University, Maastricht, The Netherlands \\ ${ }^{\mathrm{b}}$ Department of Psychiatry and Neuropsychology, Faculty of Health, Medicine and Life Sciences, European School of Neuroscience (EURON), Maastricht \\ University, Maastricht, The Netherlands
}

\section{A R T I C L E I N F O}

\section{Article history:}

Received 24 December 2014

Received in revised form

6 March 2015

Accepted 12 March 2015

Available online 28 March 2015

Keywords:

Cognition

Translational

Drug research

Cholinergic

Event-related potentials

Coherence analysis

\begin{abstract}
A B S T R A C T
It has been shown to be difficult to predict whether cognition-enhancing effects of drugs in animal studies have the same effect in humans. Various issues in translating findings from animal to human studies can be identified. Here we discuss whether EEG could be considered as a possible tool to translate the effects of cognition enhancers across species. Three different aspects of EEG measures are evaluated: frequency bands, event-related potentials, and coherence analysis. On basis of the comparison of these measures between species, and effects of drugs that improve or impair memory performance (mainly cholinergic drugs), it appears that event-related potentials and coherence analyses could be considered as potential translational tools to study cognition-enhancing drug effects in rodents and animals.
\end{abstract}

(c) 2015 Elsevier B.V. All rights reserved.

\section{Introduction}

The development of cognition enhancing drugs is to be a great challenge. Although many drugs have been characterized as having a positive effect in animal models of learning and memory, the effectiveness of most of these drugs in humans is very limited. Several reasons can be offered for the poor translation of the cognition enhancing drugs (Sarter, 2006). First, it could be argued that the validity of models used in animal research have poor translational value. Second, side effects and toxicological issues may play an important limiting factor during the development of novel drugs. A third reason for the poor translational value could be related to differences in pharmacodynamics and pharmacokinetics between animals and humans (Blokland et al., 2014).

There are different levels at which the effects of drugs on animals and humans can be compared (see Table 1). At a first level the neuronal functions can be compared. This usually involves in vitro models in which the interaction of the drug with specific receptors of animals or humans can be evaluated. At this level the intracellular signaling pathways can also be examined.

A second level could reflect the drug effects in a mechanistic level. Here it can be evaluated whether the drug influences neurotransmitter levels or metabolites (e.g., Pepeu and Giovannini, 2010). An

\footnotetext{
* Correspondence to: Neuropsychology and Psychopharmacology, Faculty of Psychology and Neuroscience, Maastricht University, P.O. Box 616, 6200 MD Maastricht, The Netherlands. Tel.: + 31433881903 .

E-mail address: a.blokland@maastrichtuniversity.nl (A. Blokland).
}

example of this is the evaluation of a drug in models of long-term potentiation (LTP), a neurophysiological model of synaptic plasticity (e.g., Blokland and Boess, 2008). Additional models can be used to examine whether the drug enters the brain and which areas are target locations for a drug (e.g., Shaffer, 2010). These models give insight into the mechanistic properties of the drug, whereby microdialysis and LTP provide additional information of a putative effect on cognition.

A third proposed level is related to EEG, which is the main topic of this paper and will be discussed in much greater detail below. Briefly, this method evaluates the effects of drugs on brain activity. At this level drug effects can be examined in different manners (see Table 2). First, the effects can be examined with respect to the power of different frequency bands which correspond to different behavioral states of a subject (from attentive to asleep). Second, drug effects on event-related potentials (ERPs) can be investigated. These ERPs reflect the brain activity related to stimulus presentation or to a response that has to be made. There are various ERP paradigms that can be applied in animals as well in humans. Finally, EEG methods can be used to examine the connectivity between different regions of the brain. Also this method can be used in different species.

The fourth level that can be defined to compare preclinical and clinical studies is the use of behavioral models. Here concepts of cognitive functions are translated into human and animal models. At this level translation of cognitive functions has been difficult since humans and animals vary to a great extent as to the behavioral repertoire to perform certain tasks (van der Staay, 2006; 
Table 1

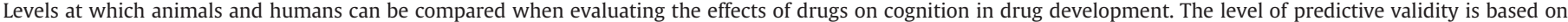
general assumptions.

\begin{tabular}{|c|c|c|c|c|}
\hline Level & Model & Aim & Validity & Reference \\
\hline 1 & In vitro & $\begin{array}{l}\text { Evaluation of target selectivity (binding properties), receptor profiling, } \\
\text { intracellular signaling }\end{array}$ & Low & (No reference) \\
\hline 2 & Mechanistic & Microdialysis, LTP, pharmacodynamics, pharmacokinetics, PET & Low & $\begin{array}{l}\text { (Blokland and Boess, 2008; Pepeu and Giovannini, 2010; } \\
\text { Shaffer, 2010) }\end{array}$ \\
\hline \multirow[t]{3}{*}{3} & Functional & EEG & Low & \\
\hline & & ERP & High & (See this paper) \\
\hline & & Connectivity & High & \\
\hline 4 & Behavioral & Animal models & Moderate & (Homberg, 2013) \\
\hline
\end{tabular}

LTP: long-term potentiation; PET: positron emission tomography EEG: electroencephalogram; ERP: event-related potential.

Table 2

Overview of the different methods that can be used to examine EEG related measures in humans and animals.

\begin{tabular}{|c|c|c|c|}
\hline Method & What is measured & Paradigms & Disease related \\
\hline Power spectra & $\begin{array}{l}\text { The power in different frequency bands (beta, alpha, theta, delta, } \\
\text { gamma) }\end{array}$ & Recording resting EEG, or during a certain state & Non-specific \\
\hline ERP & $\begin{array}{l}\text { Synchronized activity as a response to a stimulus or a response } \\
\text { that has to be made by a subject. Typically latency and voltage of } \\
\text { peaks in ERP wave pattern }\end{array}$ & $\begin{array}{l}\text { Auditory-evoked potential, visually-evoked } \\
\text { potential, mismatch negativity, oddball, sensory } \\
\text { gating, readiness potential }\end{array}$ & $\begin{array}{l}\text { Auditory-visual } \\
\text { evoked potential: } \\
\text { non-specific. } \\
\text { Mismatch } \\
\text { negativity/sensory } \\
\text { gating: } \\
\text { schizophrenia } \\
\text { Readiness } \\
\text { potential: basal } \\
\text { ganglia functions }\end{array}$ \\
\hline Connectivity & Coherent activity in different regions in the brain & Recording resting EEG, or during a certain state & Non-specific \\
\hline
\end{tabular}

Homberg, 2013). However, recent developments show that some complex human functions can be modeled in rodents, such as the intra-/extra-dimensional shift task (Birrell and Brown, 2000) and touch screen tests that correspond to a validated memory test battery for humans, such as the CANTEB test (e.g., Horner et al., 2013). To these behavioral paradigms different models can be applied to mimic brain diseases, e.g., pharmacological, lesions, and genetic modified animals (e.g., van Goethem et al., 2014).

There has been much research that relates to use of levels 1 , 2 and 4 in translational studies. However, the use of EEG as a translational model to investigate cognition enhancing drugs is still relatively limited. In this paper we would like to highlight the various manners of EEG measures that could be applied in translational studies. Further, we describe data in which the effects of the same drug were tested in the same EEG paradigm in animals and man. We will provide support for the notion that EEG measures can be used for various purposes: central effects of drugs, biomarkers (of synaptic plasticity) or predictor of cognition enhancing properties of drugs.

\section{The use of EEG in humans and animals}

In humans electrodes can be placed at the skull and the electrical activity of the brain can be picked up at various places. Current EEG methods in humans are based on standard based positions of the electrodes in order to make studies more comparable (Jasper, 1958). In rodent studies the location of the electrodes is based on stereotactic coordinates and may differ between studies. But there are other essential differences between animals and man when measuring EEG. Electrode positions in humans provide the opportunity to mainly assess cortical processes whereas in animals brain activity from deeper structures can be measured. Thus, in animals local field potentials can actually be measured in a brain structure of interest by positioning electro- des in predetermined brain areas. This usually results in higher voltages being measured in animals (about $10 \mu \mathrm{V}$ ) as compared to humans (about $1 \mu \mathrm{V}$ ). This may lead to more sensitive measurements in animals.

Another point that can be mentioned is that the test-retest reliability of EEG parameters in humans is optimal when subjects are tested with their eyes closed. Clearly this is not the case when measuring EEG in behaving animals, let alone anesthetized animals (Boeijinga, 2010). A fourth important difference between animals and humans is the shape of the cortex. Rats and mice (mostly used for these studies) have a smooth cortical surface whereas in humans the cortical surface is characterized by gyri and sulci. This may have consequences if one is interested in the source of a signal that is picked-up at the surface of the skull. Thus, if a strong signal is picked-up at a certain location the source of this signal may not necessarily be near the location of the electrode (e.g., Kirschstein and Köhling, 2009). Another main difference related to the anatomy of the brain and the effect on the EEG signal is related to the position of the hippocampus. In humans this structure is located in the medial temporal lobe and it is difficult to measure EEG from this structure (only in epileptic patients hippocampal EEG recordings can be done). In rodents the hippocampus is situated just below the cortical mantle and has a great influence on recordings at the cortex, such as the vertex. Taken together, these differences suggest that recordings at the surface in humans and animals may not be comparable.

Irrespective of the differences, various studies have examined the effects of drugs in animals in order to predict their effectiveness in humans. A concise overview of these studies will be given below.

Before discussing the different methods another application of EEG should be mentioned. This deals with the use of EEG as a possible biomarker of central action or cognitive function. When drugs have shown to be effective in preclinical studies it is of great interest at what dose the drug will be effective in humans, and 
whether the drug affects brain function. Since EEG is a much more sensitive measure of changes in brain function as compared to behavioral parameters (Luck, 2014), changes in EEG (irrespective of the method applied) could be interpreted in terms of a central effect of a drug.

\section{EEG-power spectra}

When analyzing the EEG on the basis of the frequencies it should be noted that various frequency bands have been described which all have been associated with states of consciousness. Although the border of the frequency bands differs slightly between different studies, several frequency bands can be distinguished in the raw EEG signal of humans (Basar and Guntekin, 2013). When the EEG is characterized with slow waves with a high amplitude this is generally associated with deep sleep. These waves are known as delta waves and the EEG is predominantly characterized by frequencies in the bandwidth of 0 $4 \mathrm{~Hz}$. The next band is called the theta band $(4-8 \mathrm{~Hz})$ and can predominantly be found when a subject is snoozing or just before falling asleep or waking up. However, theta has also been associated with cognitive effort (Smit et al., 2005). The alpha band (8-14 Hz) can be found when a subject is passively awake. When a subject is alert and concentrated an increase in the frequencies in the beta band $(14-30 \mathrm{~Hz})$ can be found in the EEG. When higher frequencies can be found in the EEG these are called gamma waves $(30-80 \mathrm{~Hz})$ which have been associated with higher cognitive functions.

On basis of these descriptions of the sleep-wake stages and the associated EEG oscillations it could be suggested that EEG frequencies in the beta, theta and the gamma band are related to cognition. However, it has been suggested that especially the theta and gamma oscillations should be considered as relevant for cognitive functions (Cantero and Atienza, 2005; Franca et al., 2014; Roux and Uhlhaas, 2014). Before translating these frequency-based oscillations between species at least some issues need to be clarified. A first issue is obviously related to the site of recording. If a comparison is made between species rat electrodes should be located at the scull and not be located below the dura (i.e., intracerebral recordings). As mentioned above, the location at the scull (e.g., frontal or parietal regions) is also relevant for comparison.

A second issue is related to the comparison of the frequency bands across species. It needs to be established that for example theta oscillations in animals can be compared with theta oscillations in man. Thus, it has been suggested that theta are much more present in rodent EEG as compared to monkeys and humans (Niedermeyer; 2008). Further, a recent study claimed that the theta frequency of animals $(4-10 \mathrm{~Hz})$ is functionally comparable to a slow rhythm that can be found in the human hippocampus $(1-4 \mathrm{~Hz})$.

A third issue is to have clear biomarkers of human EEG in different brain diseases, especially related to cognitive functions (Basar and Guntekin, 2013). Only when we have identified these specific biomarkers for each disease it could be examined whether these specific markers can be modeled in animals. A recent review on biomarkers concluded that in human studies the search for EEG-related biomarkers has not provided clear diagnostic tools yet (McLoughlin et al., 2014). Also, there is not much consistency when comparing EEG in animal models of Alzheimer's disease with those in Alzheimer patients (de Waal et al., 2012; Babiloni et al., 2013). Considering this status on biomarkers and their translational potential it is clear that more studies are needed, especially large samples that include genetic and developmental data. Only when relations can be found between EEG and individual genes the true value of EEG as a biomarker can be evaluated (McLoughlin et al., 2014).

If we would like to compare the characteristics of drug effects on EEG the most suitable comparison is the comparison of animals and human in resting EEG. Another requirement for a species comparison is that the EEG recordings should not be from intracranial electrodes. When taken these constraints into account, there are only a very limited number of studies that allows comparison of animal and human studies in which cognition enhancing drugs are tested. Since mostly acetylcholinesterase inhibitors have been investigated in both animals and humans in comparable conditions a brief overview of these studies is given below.

A recent animal study examined the effects of current drugs that are being prescribed as cognition enhancing drugs for Alzheimer's disease (Ahnaou et al., 2014). All drugs (donepezil, rivastigmine, tacrine, galantamine and memantine) appeared to have the same effect on the EEG, although they differ in their mechanism of action, i.e., cholinesterase inhibition or NMDA antagonist. They all increased the proportion of theta (lower bandwidth, $4.5-6 \mathrm{~Hz})$ and gamma $(30.5-50 \mathrm{~Hz})$ oscillations. In another study memantine only increased gamma oscillations without affecting other frequency bands (Hiyoshi et al., 2014). Further, the findings with respect to the effects of cholinergic drugs differ from another study in which the effects were examined on various frequency bands (Dimpfel, 2005). This study showed that theta was in most areas decreased after administration of cholinesterase inhibitors. Unfortunately, gamma frequencies were not examined in this study. In another study, scopolamine and donepezil did not affect theta oscillations in the hippocampus whereas theta was decreased after nicotinic treatment (Sambeth et al., 2003).

Interestingly, in contrast to the cognition enhancing effect in animal studies (e.g., Prickaerts et al., 2005; Sambeth et al., 2007), administering cholinesterase inhibitors in healthy human volunteers (or even older subjects) generally does not improve cognitive functions, but rather seems to have no effect or even impairs performance (see Balsters et al., 2011). And although the memory performance is not improved, some effects can be found on EEG frequency bands in humans. For example, one study with healthy young volunteers showed that after galantamine treatment the alpha power was increased whereas no changes in theta were observed (Holl et al., 1992). In older healthy volunteers a decrease in alpha and beta power was observed after donepezil treatment in healthy older participants (Balsters et al., 2011). In another study that examined the effects of the acetylcholinesterae inhibitor physostigmine in older healthy volunteers showed that theta and delta activity was increased (Pfefferbaum et al., 1979). On the other hand, a slowing of the peak alpha frequency was found.

Taken together, even though test parameters were comparable to some extend in the studies described above, these few studies show a rather high variability in effects, between- and within species. Although this may be related to various experimental conditions in the different studies, these data do not support the notion that power spectra of frequency bands can be considered as a reliable tool to compare the effects of cognition enhancing drugs across species.

\section{Task related EEG-ERPs}

In contrast to power spectra, there are relatively more studies in which the effects of cognition enhancing drugs are evaluated in event-related potentials (ERPs). ERPs have a typical wave form and reflect brain responses to a stimulus/response. This response is dependent on the type of stimulus or response to be made (Hillyard, 1993). The variables that can be taken from these wave forms are the amplitude of a peak (positive or negative) and the latency of a peak. In humans, deflections that occur before $300 \mathrm{~ms}$ are usually associated with pre-attentive processes. The positive peak that can be found after about $300 \mathrm{~ms}$ is related to attentional processes. Peaks which appear later than that are generally 
associated with cognitive evaluation processes. In general ERPs appear to be comparable between species, as has been shown in a previous study (Sambeth et al., 2003; Sambeth et al., 2004).

There are various ERPs that can be measured in both animals and man (see Table 3). These ERPs are generally measured during conditions in which a subject is not required to perform a task, which is the advantage of these paradigms. The simple paradigms are the ERPs than can be found after presenting an auditory or visual stimulus (AEP and VEP, respectively). These ERPs reflect basic stimulus processing. The mismatch negativity (MMN), oddball (OB) and P50 gating ERPs reflect some (pre-)attentive processes that involve some more complex processing of information when compared to AEP en VEP (Duncan et al., 2009; Kenemans and Kahkonen, 2011). Moreover, the MMN, OB and P50 have also be been linked with deficits in early cognitive processing deficits observed in brain diseases and aging in humans and animals (Umbricht et al., 2005; Javitt et al., 2008; Ashford et al., 2011; Naatanen et al., 2011; Harms et al., 2014). Of note, sensory gating in humans is usually measured with the P50 whereas in animals this is typically measured with P20-N40 components.

Based on the findings that these different ERPs are disturbed in aging and diseases, it can be inferred that reversing these changes in the ERPs via drug treatment may indicate an improvement in cognitive functions. Thus, when we observe a reversal of the disease-specific ERP in animals we would expect a similar effect in humans. Various studies have studied these relations. For example, drug treatments in animals and transgenic mice appear to have comparable effects as in humans (Amann et al., 2010). Also for the MMN there appears to be a good relation between animals and humans, albeit that the translation appears to more valid for glutamatergic and cholinergic and not for monoaminergic neurotransmission (Todd et al., 2013). The P300 that can be measured in the OB paradigm seems to be sensitive to cholinergic drugs in both animals (in animals more likely to be related to a pre-attentive P300 component, the P3a Grupe et al., 2014; Laursen et al., 2014) and man (Werber et al., 2003; Klinkenberg et al., 2013). Drug effects on the P50 paradigm (sensory gating) also appear to be comparable between species. This has been found for nicotinic drugs (Olincy et al., 2006; Radek et al., 2012) and for clozapine (Chung and Remington, 2005; Smucny et al., 2014).

Another approach may be to use a simple ERP (e.g. AEP) and examine the effects of drugs in animals (EEG and memory performance), and see whether you can find an effect on the EEG in humans. This may then potentially predict a cognition enhancing effect in humans. This was attempted in two studies in which the effects of cholinergic drugs were examined on object recognition memory in rats (Sambeth et al., 2007) and in humans in which auditory stimuli were used (Klinkenberg et al., 2013). In the human study it was found that the latency of the early components was delayed after biperiden and that these were shortened after rivastigmine treatment. In the animal study, scopolamine impaired memory performance and nicotine and donepezil were able to reverse this drug-induced memory impair- ment. When examining the EEG, the early peaks were higher (N1 peak, about $50 \mathrm{~ms}$ ) and lower (N2 peak, about $200 \mathrm{~ms}$ ) which could not be reversed by nicotine or donepezil. When summarizing these data it appears that the effects of cholinergic drugs on a relative simple auditory stimulus are different and that a comparison with memory performance does not seem very likely.

Taken together, simple ERPs (e.g., AEP and VEP) do not seem to predict cognition enhancing effect in animals. It appears that the drug effects on the different peaks differ between species. There is more converging evidence that (pre)attentive-related ERPs can be considered as relevant biomarkers for cognitive dysfunction in brain diseases and that drug effects are comparable between species. This implies that at least MMN, OB and P50 gating paradigms could be considered as relevant paradigms for comparing drug effects between species.

\section{EEG-connectivity}

Another approach to use EEG related measures as a potential marker for cognition-enhancing is the evaluation of the connectivity between different brain structures. There seems to be an increasing interest in understanding cognitive functions in terms of brain networks (Sporns, 2014). Of note, these network analyses are normally examined using fMRI (e.g., resting state connectivity) and MEG methods but EEG can also be applied. Disturbances in network connectivity have, amongst other diseases, been observed in Alzheimer's disease (de Haan et al., 2012; Dubovik et al., 2013).

Some human studies have applied this method to examine the effects of cholinergic drugs in Alzheimer's disease. For example, one study showed that functional connectivity in the hippocampus was disturbed in Alzheimer patients and that this correlated with cognitive performance (Goveas et al., 2011). After 12 weeks of donepezil treatment hippocampal connectivity was improved and an improved connectivity was found with the dorsolateral prefrontal cortex and the middle frontal gyrus. This improved connectivity was associated with an improved cognitive performance. In another study an improved connectivity between the left and right dorsolateral prefrontal cortex was found (Zaidel et al., 2012). Both studies used fMRI methods to show these changes in brain network connectivity. In a MEG study it was found that scopolamine decreased the inter-hemispheric and left intra-hemispheric coherence in the theta band in older subjects (Osipova et al., 2003).

In an animal study it was shown that scopolamine increased the coherent activity in slow frequency oscillations (leftward shift in the oscillatory activity in the network) (Ahnaou et al., 2014). This study also showed that cognition enhancers (actelylcholinesterase inhibitors and memantine) increased the connectivity between the hippocampus and the frontal cortex. In one other study ketamine was used as a model of schizophrenia (Palenicek et al., 2011). Here it was found that cognitive deficits were associated with a stronger coherence across different electrodes.

Table 3

ERP paradigms that can be applied in humans and animals.

\begin{tabular}{|c|c|c|c|}
\hline ERP paradigm & Trigger & Peak & Location (human/rodent) \\
\hline Auditory evoked potential & Onset of a tone & (Various) & Parietal/vertex, hippocampus \\
\hline Visually evoked potential & Onset of a visual stimulus & (Various) & Occipital/vertex, hippocampus \\
\hline Mis-match negativity & & N100-200 in humans, between $50-100$ in rats & Fronto-central/vertex \\
\hline Oddbal & Targets versus familiar stimuli & P300 & $\begin{array}{l}\text { Parieto-central/vertex, } \\
\text { hippocampus }\end{array}$ \\
\hline Sensory gating (P50) & Two similar tones with a short inter-stimulus interval & $\mathrm{P} 50^{\mathrm{a}}$ & Frontal/vertex, hippocampus \\
\hline
\end{tabular}

\footnotetext{
${ }^{\text {a }}$ For animals the latency of the peak has been discussed (see text).
} 
These data do show that connectivity measures can be used to see effects of cognition enhancing drugs and that improved connectivity (hippocampus-frontal cortex) is associated with improved cognitive performance in both species. It should be noted that only some studies have been performed and that these data need to be substantiated in order to show the validity of these measures. Another point to be mentioned is that caution is required when using brain network analyses when comparing different species (De Vico Fallani et al., 2014).

\section{Conclusion}

In this short overview an attempt was made to evaluate the use of EEG-related measures as translational tools to investigate cognition enhancing drugs. Here three different EEG related measures were examined: EEG power spectra, ERPs and connectivity. Of note, the number of studies that examined the effects of cognition enhancing drugs using EEG measures is relatively small. In order to make stronger conclusions, additional animal and human studies for the different types of EEG measures are required. Further, more consistency in animal studies is required with respect to electrode placement, like in human EEG studies. This will increase the comparison between studies. At present the ERP-related measures appear to have a good translational validity (except AEPs). This is related to the comparability of ERPs between species and to the fact that ERPs can be linked with specific cognitive features. Connectivity measures seem to have a high potential as a translational tool to test cognition enhancers in different species. Taken together, EEG measures hold a good promise to be used as a tool to compare cognition enhancing effect between species.

\section{References}

Ahnaou, A., Huysmans, H., Jacobs, T., Drinkenburg, W.H., 2014. Cortical EEC oscillations and network connectivity as efficacy indices for assessing drugs with cognition enhancing potential. Neuropharmacology 86, 362-377.

Amann, L.C., Gandal, M.J., Halene, T.B., Ehrlichman, R.S., White, S.L., McCarren, H.S., Siegel, S.J., 2010. Mouse behavioral endophenotypes for schizophrenia. Brain Res. Bull. 83, 147-161.

Ashford, J.W., Coburn, K.L., Rose, T.L., Bayley, P.J., 2011. P300 energy loss in aging and Alzheimer's disease. J. Alzheimers Dis. 26 (Suppl. 3), S229-S238.

Babiloni, C., Infarinato, F., Aujard, F., Bastlund, J.F., Bentivoglio, M., Bertini, G., Del Percio, C. Fabene, P.F., Forloni, G., Herrero Ezquerro, M.T., Noe, F.M., Pifferi, F., Ros-Bernal, F. Christensen, D.Z., Dix, S., Richardson, J.C., Lamberty, Y., Drinkenburg, W., Rossini, P.M. 2013. Effects of pharmacological agents, sleep deprivation, hypoxia and transcrania magnetic stimulation on electroencephalographic rhythms in rodents: towards translational challenge models for drug discovery in Alzheimer's disease. Clin. Neurophysiol. 124, 437-451.

Balsters, J.H., O'Connell, R.G., Martin, M.P., Galli, A., Cassidy, S.M., Kilcullen, S.M., Delmonte, S., Brennan, S., Meaney, J.F., Fagan, A.J., Bokde, A.L., Upton, N., Lai, R. Laruelle, M., Lawlor, B., Robertson, I.H., 2011. Donepezil impairs memory in healthy older subjects: behavioural, EEG and simultaneous EEG/fMRI biomarkers. PLoS One 6, e24126.

Basar, E., Guntekin, B., 2013. Review of delta, theta, alpha, beta, and gamma response oscillations in neuropsychiatric disorders. Suppl. Clin. Neurophysiol. $62,303-341$

Birrell, J.M., Brown, V.J., 2000. Medial frontal cortex mediates perceptual attentiona set shifting in the rat. J. Neurosci. 20, 4320-4324.

Blokland, A., Boess, F., 2008. Use of behavioral and LTP models in the development of memory-improving drugs. Expert Opin. Drug Discov. 3, 1067-1080.

Blokland, A., van Goethem, N., Heckman, P., Schreiber, R., Prickaerts, J., 2014. Translational issues with the development of cognition enhancing drugs. Front. Neurol. 5, 190.

Boeijinga, P.H., 2010. Electroencephalography, In: Stolerman, I.P. (Ed.), Encyclopedia of Psychopharmacology. Springer-Verlag, Berlin, pp. 462-471.

Cantero, J.L., Atienza, M., 2005. The role of neural synchronization in the emergence of cognition across the wake-sleep cycle. Rev. Neurosci. 16, 69-83.

Chung, C., Remington, G., 2005. Predictors and markers of clozapine response. Psychopharmacology 179, 317-335.

de Haan, W., van der Flier, W.M., Koene, T., Smits, L.L., Scheltens, P., Stam, C.J., 2012 Disrupted modular brain dynamics reflect cognitive dysfunction in Alzheimer's disease. Neuroimage 59, 3085-3093.
De Vico Fallani, F., Richiardi, J., Chavez, M., Achard, S., 2014. Graph analysis of functional brain networks: practical issues in translational neuroscience. Philos. Trans. R. Soc. Lond. B Biol. Sci. 369.

de Waal, H., Stam, C.J., de Haan, W., van Straaten, E.C., Scheltens, P., van der Flier, W.M., 2012. Young Alzheimer patients show distinct regional changes of oscillatory brain dynamics. Neurobiol. Aging 33 (1008), e1025-1031.

Dimpfel, W., 2005. Pharmacological modulation of cholinergic brain activity and its reflection in special EEG frequency ranges from various brain areas in the freely moving rat (Tele-Stereo-EEG). Eur. Neuropsychopharmacol. 15, 673-682.

Dubovik, S., Bouzerda-Wahlen, A., Nahum, L., Gold, G., Schnider, A., Guggisberg, A.G., 2013. Adaptive reorganization of cortical networks in Alzheimer's disease. Clin. Neurophysiol. 124, 35-43.

Duncan, C.C., Barry, R.J., Connolly, J.F., Fischer, C., Michie, P.T., Naatanen, R., Polich, J., Reinvang, I., Van Petten, C., 2009. Event-related potentials in clinical research: guidelines for eliciting, recording, and quantifying mismatch negativity, P300, and N400. Clin. Neurophysiol. 120, 1883-1908.

Franca, A.S., do Nascimento, G.C., Lopes-Dos-Santos, V., Muratori, L., Ribeiro, S., Lobao-Soares, B., Tort, A.B., 2014. Beta2 oscillations $(23-30 \mathrm{~Hz})$ in the mouse hippocampus during novel object recognition. Eur. J. Neurosci. 40, 3693-3703.

Goveas, J.S., Xie, C., Ward, B.D., Wu, Z., Li, W., Franczak, M., Jones, J.L., Antuono, P.G., Li, S.J., 2011. Recovery of hippocampal network connectivity correlates with cognitive improvement in mild Alzheimer's disease patients treated with donepezil assessed by resting-state fMRI. J. Magn. Reson. Imaging 34, 764-773.

Grupe, M., Grunnet, M., Laursen, B., Bastlund, J.F., 2014. Neuropharmacological modulation of the P3-like event-related potential in a rat two-tone auditory discrimination task with modafinil and NS9283, a positive allosteric modulator of alpha4beta2 nAChRs. Neuropharmacology 79, 444-455.

Harms, L., Fulham, W.R., Todd, J., Budd, T.W., Hunter, M., Meehan, C., Penttonen, M., Schall, U., Zavitsanou, K., Hodgson, D.M., Michie, P.T., 2014. Mismatch negativity $(\mathrm{MMN})$ in freely-moving rats with several experimental controls. PLoS One 9, e110892.

Hillyard, S.A., 1993. Electrical and magnetic brain recordings: contributions to cognitive neuroscience. Curr. Opin. Neurobiol. 3, 217-224.

Hiyoshi, T., Kambe, D., Karasawa, J., Chaki, S., 2014. Differential effects of NMDA receptor antagonists at lower and higher doses on basal gamma band oscillation power in rat cortical electroencephalograms. Neuropharmacology 85, 384-396.

Holl, G., Straschill, M., Thomsen, T., Fischer, J.P., Kewitz, H., 1992. Effect of the cholinesterase inhibiting substance galanthamine on human EEG and visual evoked potentials. Electroencephalogr. Clin. Neurophysiol. 82, 445-452.

Homberg, J.R., 2013. Measuring behaviour in rodents: towards translational neuropsychiatric research. Behav. Brain Res. 236, 295-306.

Horner, A.E., Heath, C.J., Hvoslef-Eide, M., Kent, B.A., Kim, C.H., Nilsson, S.R., Alsio, J., Oomen, C.A., Holmes, A., Saksida, L.M., Bussey, T.J., 2013. The touchscreen operant platform for testing learning and memory in rats and mice. Nat. Protoc. 8, 1961-1984.

Jasper, H., 1958. The ten-twenty electrode system of the international federation. Electroencephalogr. Clin. Neurophysiol. 10, 371-375.

Javitt, D.C., Spencer, K.M., Thaker, G.K., Winterer, G., Hajos, M., 2008. Neurophysiological biomarkers for drug development in schizophrenia. Nat. Rev. Drug Discov, 7, 68-83.

Kenemans, J.L., Kahkonen, S., 2011. How human electrophysiology informs psychopharmacology: from bottom-up driven processing to top-down control. Neuropsychopharmacology 36, 26-51.

Kirschstein, T., Köhling, R., 2009. What is the source of the EEG? Clin. EEG Neurosci. 40, 146-149.

Klinkenberg, I., Blokland, A., Riedel, W.J., Sambeth, A., 2013. Cholinergic modulation of auditory processing, sensory gating and novelty detection in human participants. Psychopharmacology 225, 903-921.

Laursen, B., Mork, A., Kristiansen, U., Bastlund, J.F., 2014. Hippocampal P3-like auditory event-related potentials are disrupted in a rat model of cholinergic degeneration in Alzheimer's disease: reversal by donepezil treatment. J. Alzheimers Dis. 42, 1179-1189.

Luck, S.J., 2014. An Introduction to the Event-Related Potential Technique. MIT Press, Cambridge MA, USA.

McLoughlin, G., Makeig, S., Tsuang, M.T., 2014. In search of biomarkers in psychiatry: EEG-based measures of brain function. Am. J. Med. Genet. B Neuropsychiatr. Genet. 165B, 111-121.

Naatanen, R., Kujala, T., Kreegipuu, K., Carlson, S., Escera, C., Baldeweg, T., Ponton, C., 2011. The mismatch negativity: an index of cognitive decline in neuropsychiatric and neurological diseases and in ageing. Brain 134, 3435-3453.

Niedermeyer, E., 2008. Hippocampic theta rhythm. Clin. EEG Neurosci. 39, 191-193.

Olincy, A., Harris, J.G., Johnson, L.L., Pender, V., Kongs, S., Allensworth, D., Ellis, J., Zerbe, G.O., Leonard, S., Stevens, K.E., Stevens, J.O., Martin, L., Adler, L.E., Soti, F., Kem, W.R., Freedman, R., 2006. Proof-of-concept trial of an alpha7 nicotinic agonist in schizophrenia. Arch. Gen. Psychiatry 63, 630-638.

Osipova, D., Ahveninen, J., Kaakkola, S., Jaaskelainen, I.P., Huttunen, J., Pekkonen, E., 2003. Effects of scopolamine on MEG spectral power and coherence in elderly subjects. Clin. Neurophysiol. 114, 1902-1907.

Palenicek, T., Fujakova, M., Brunovsky, M., Balikova, M., Horacek, J., Gorman, I., Tyls, F, Tislerova, B., Sos, P., Bubenikova-Valesova, V., Hoschl, C., Krajca, V., 2011. Electroencephalographic spectral and coherence analysis of ketamine in rats: correlation with behavioral effects and pharmacokinetics. Neuropsychobiology 63, 202-218.

Pepeu, G., Giovannini, M.G., 2010. Cholinesterase inhibitors and memory. Chem. Biol. Interact. 187, 403-408. 
168

A. Blokland et al. / European Journal of Pharmacology 759 (2015) 163-168

Pfefferbaum, A., Davis, K.L., Coulter, C.L., Mohs, R.C., Tinklenberg, J.R., Kopell, B.S., 1979. EEG effects of physostigmine and choline chloride in humans. Psychopharmacology 62, 225-233.

Prickaerts, J., Sik, A., Van Der Staay, F.J., De Vente, J., Blokland, A., 2005. Dissociable effects of acetylcholinesterase inhibitors and phosphodiesterase type 5 inhibitors on object recognition memory: acquisition versus consolidation. Psychopharmacology 177, 381-390.

Radek, R.J., Robb, H.M., Stevens, K.E., Gopalakrishnan, M., Bitner, R.S., 2012. Effects of the novel alpha7 nicotinic acetylcholine receptor agonist ABT-107 on sensory gating in DBA/2 mice: pharmacodynamic characterization. J. Pharmacol. Exp. Ther. 343, 736-745.

Roux, F., Uhlhaas, P.J., 2014. Working memory and neural oscillations: alphagamma versus theta-gamma codes for distinct WM information? Trends Cogn. Sci. 18, 16-25.

Sambeth, A., Maes, J.H., Quian Quiroga, R., Coenen, A.M., 2004. Effects of stimulus repetitions on the event-related potential of humans and rats. Int. J. Psychophysiol. 53, 197-205.

Sambeth, A., Maes, J.H., Van Luijtelaar, G., Molenkamp, I.B., Jongsma, M.L., Van Rijn, C.M., 2003. Auditory event-related potentials in humans and rats: effects of task manipulation. Psychophysiology 40, 60-68.

Sambeth, A., Riedel, W., Smits, L., Blokland, A., 2007. Cholinergic drugs affect novel object recognition in rats: relation with hippocampal EEG? Eur. J. Pharmacol. $572,151-159$.

Sarter, M., 2006. Preclinical research into cognition enhancers. Trends Pharmacol. Sci. 27, 602-808.

Shaffer, C.L., 2010. Defining neuropharmacokinetic parameters in CNS drug discovery to determine cross-species pharmacologic exposure-response relationships. In: Macor, J.E. (Ed.), Annual Reports in Medicinal Chemistry. Elsevier Science, Amsterdam.

Smit, A.S., Eling, P.A., Hopman, M.T., Coenen, A.M., 2005. Mental and physical effort affect vigilance differently. Int. J. Psychophysiol. 57, 211-217.

Smucny, J., Stevens, K.E., Tregellas, J.R., 2014. Acute administration of Delta (9) tetrahydrocannabinol does not prevent enhancement of sensory gating by clozapine in DBA/2 mice. Pharmacol. Biochem. Behav. 118, 22-29.

Sporns, O., 2014. Contributions and challenges for network models in cognitive neuroscience. Nat. Neurosci. 17, 652-660.

Todd, J., Harms, L., Schall, U., Michie, P.T., 2013. Mismatch negativity: translating the potential. Front. Psychiatry 4, 171.

Umbricht, D., Vyssotki, D., Latanov, A., Nitsch, R., Lipp, H.P., 2005. Deviance-related electrophysiological activity in mice: is there mismatch negativity in mice? Clin. Neurophysiol. 116, 353-363.

van der Staay, F.J., 2006. Animal models of behavioral dysfunctions: basic concepts and classifications, and an evaluation strategy. Brain Res. Rev. 52, 131-159.

van Goethem, N.P., Lardenoije, R., Kompotis, K., Bart, P.F., Rutten, B.P.F., Prickaerts, J., Steinbusch, H.W.M., 2014. Cognitive disorders: impairment, aging, and dementia. In: Vela, J.M., Maldonado, R., Hamon, M. (Eds.), In Vivo Models for Drug Discovery. Wiley-VCH Verlag GmbH \& Co. KGaA, Weinheim, Germany.

Werber, E.A., Gandelman-Marton, R., Klein, C., Rabey, J.M., 2003. The clinical use of P300 event related potentials for the evaluation of cholinesterase inhibitors treatment in demented patients. J. Neural Transm. 110, 659-669.

Zaidel, L., Allen, G., Cullum, C.M., Briggs, R.W., Hynan, L.S., Weiner, M.F., McColl, R., Gopinath, K.S., McDonald, E., Rubin, C.D., 2012. Donepezil effects on hippocampal and prefrontal functional connectivity in Alzheimer's disease: preliminary report. J. Alzheimers Dis. 31 (Suppl. 3), S221-S226. 